\title{
A atenção à saúde dos reclusos em Maputo: é viável avaliar?
}

\author{
Health care for inmates in Maputo: is it feasible to evaluate?
}

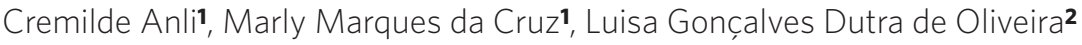

DOI: $10.1590 / 0103-1104202012710$

RESUMO O objetivo foi realizar um estudo de avaliabilidade da atenção à saúde dos reclusos no Estabelecimento Penitenciário Provincial de Maputo (EPPM) - Moçambique com base na descrição da estrutura e dos processos de atenção à saúde no EPPM e na descrição dos contextos externos e organizacionais que interferem na atenção à saúde. Estudo de caso único com abordagem qualitativa usando as técnicas de análise documental, observação direta e questionário. Verificou-se que o EPPM possui estrutura precária, falta de insumos e profissionais em número insuficiente para a assistência à saúde. Reclusos formados como educadores de pares e ou como chefes de saúde dão apoio às atividades do posto médico, gerando seu empoderamento no Estabelecimento Penitenciário (EP). A atenção à saúde do recluso em Moçambique não é objeto de debate e não está incluída nas políticas do Serviço Nacional de Saúde, o que resulta em atenção inadequada e insuficiente. O estudo sugere a importância e viabilidade de futuras pesquisas de avaliação da atenção à saúde prisional em Moçambique para que a implantação das ações seja baseada em evidências.

PALAVRAS-CHAVE Avaliação em saúde. Prisões. Política pública. Serviços de saúde.

ABSTRACT The objective of this study was to carry out an evaluability study on the health care of inmates at the Provincial Correctional Facility in Maputo (EPPM) - Mozambique, also as from the description of health care structure and processes at EPPM, as from the description of the external and organizational contexts that interfere in health care. It is a single case study of a qualitative approach that applies the techniques of document analysis, direct observation and questionnaire. It was found that EPPM offers a precarious structure, lack of inputs and insufficient number of health care professionals. Inmates trained as peer educators or as 'chiefs of health care' give support to the activities of the medical facility propitiating their empowerment within the Correctional Facility (EP). The inmate health care in Mozambique is not an object of debate and is not addressed in the policies of the National Health Service, resulting in inadequate and insufficient care. The study affirms the importance and feasibility of future research to evaluate prison health care in Mozambique so that the implementation of actions can be based on evidence.

KEYWORDS Health evaluation. Prisons. Public policy. Health services.

\footnotetext{
1 Fundação Oswaldo Cruz (Fiocruz), Escola de Saúde Pública Sergio Arouca (Ensp) - Rio de Janeiro (RJ), Brasil. marlycruz12@gmail.com

2 Universidade Federal Fluminense (UFF), Instituto de Saúde Coletiva (ISC) Niterói (RJ), Brasil.
} 


\section{Introdução}

A população reclusa no mundo demanda mais atenção à saúde do que a população em geral, embora sua efetivação nas prisões continue sendo um grande desafio. Numa conjuntura fundamentalmente inclinada para questões de segurança, a assistência médica a essa população é relegada a segundo plano. Na África, países com poucos recursos, onde o acesso aos cuidados de saúde não é garantido à maioria da população, os governos têm aversão a propor um tratamento especial aos reclusos, cuja maioria é oriunda de comunidades desfavorecidas, sem acesso aos cuidados de saúde básicos.

A população privada de liberdade tem crescido em vários países, como nos EUA, com 2.100 mil reclusos, China com 1600 mil e Brasil com uma população carcerária de 690.000 , ou o triplo das vagas existentes, o que resulta em situação precária para os presos²

A atenção à saúde no sistema penitenciário moçambicano, fundamental para garantir as condições de infraestrutura, ambientais e nutricionais adequadas para uma convivência sã, não tem sido assegurada e desenvolvida de acordo com as necessidades da população reclusa. A oferta para os serviços demandados é ínfima para uma população que desde o ano de 2005 tem crescido exponencialmente, sem o desenvolvimento e melhoria das condições físicas e estruturais dos Estabelecimentos Penitenciários (EPs) do País. Atualmente, a capacidade de internamento no País é de 8.498 vagas, sendo $97 \%$ da população recluída do sexo masculino, majoritariamente jovem ${ }^{3}$.

Gráfico 1. Crescimento da população reclusa em Moçambique

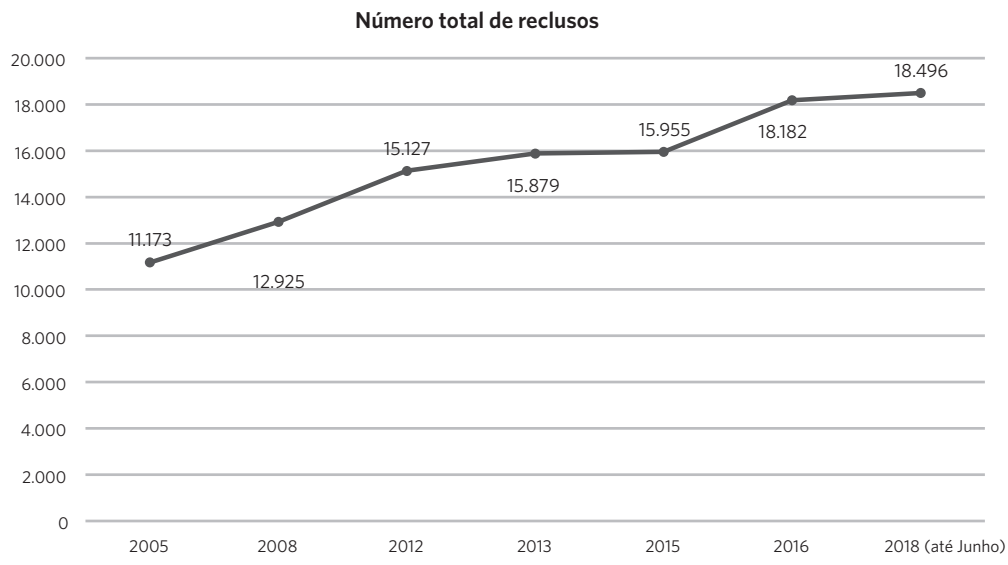

A consequência imediata do aumento do número de indivíduos nos EPs é a dificuldade na classificação e separação de reclusos consoante o crime e idade, como também garantir uma boa reabilitação. Também, a superlotação inabilita a instituição a prover a alimentação adequada bom saneamento e serviços de saúde adequados, aumentando, assim, a incidência de doenças ${ }^{4}$. A ocorrência dessas situações nos EPs é sinal de negligência e aparente abandono da parte do governo a esse grupo populacional.
Segundo Kölling et al. ${ }^{\mathbf{5}}$, a negligência no sistema penitenciário acontece de várias formas, e uma delas é a falta de saneamento básico, que pode determinar o aparecimento de doenças tais como cólera, malária, parasitoses, febre tifoide e doenças de pele. Esse crescimento da população penal requer o aumento do pessoal em geral, desde agentes penitenciários até profissionais de saúde para atender a demanda.

De acordo com o que consta na Constituição da República de Moçambique (CRM) 
[...] todos os cidadãos têm o direito à assistência médica e sanitária, nos termos da lei, bem como o dever de promover e defender a saúde pública. E, o Estado promove a extensão da assistência médica e sanitária e a igualdade de acesso de todos os cidadãos ao gozo deste direito6(26).

Entende-se, assim, que o Estado deve assumir a responsabilidade relativamente às doenças que o indivíduo possa adquirir durante o cumprimento da pena em situações em que as atividades de educação sanitárias ou preventivas são inexistentes ${ }^{7}$.

O Sistema Penitenciário Moçambicano em nível provincial estrutura-se por meio dos Estabelecimentos Penitenciários Regionais (3), Provinciais (9), Especiais (4) e Distritais (67). De acordo com o relatório do Serviço Nacional Penitenciário (Sernap), a atenção à saúde da população recluída em todo o País é garantida em 19 postos de saúde, cujo atendimento é de horário parcial nos dias úteis, à exceção de poucos que funcionam em tempo integral, i.e., os EPs Regionais Norte e Centro, Provinciais de Cabo Delgado, Tete e Maputo. Tais unidades sanitárias são de tamanho reduzido, algumas com internamento de curta duração, e contam com uma equipe de três médicos generalistas em todo País ${ }^{8}$.

As Regras Mínimas das Nações Unidas para o Tratamento de Reclusos (Regras de Mandela) ${ }^{\mathbf{9}}$ estabelecem que a prestação de serviços médicos aos reclusos é da responsabilidade do Estado.

Os reclusos devem poder usufruir dos mesmos padrões de serviços de saúde disponíveis à comunidade e ter acesso gratuito aos serviços de saúde necessários, sem discriminação em razão da sua situação jurídica9(8).

O Sistema Penitenciário em Moçambique encara dificuldades relacionadas com a infraestrutura, alocação de recursos humanos com capacidade assistencial e existência de doenças no meio da população reclusa tais como Aids e outras Infecções de Transmissão Sexual (ITS), tuberculose (TB), malária, doenças de pele e até problemas nutricionais. Do conjunto das diferentes enfermidades, as doenças transmissíveis constituem o principal problema de saúde em meio penitenciário. Essa situação torna-se motivo de atenção especial quando esses cidadãos se beneficiam, nos termos da lei, de alguma saída e regressam à convivência comunitária, podendo gerar repercussões na dinâmica social da transmissão e sua reinfecção ${ }^{10}$.

Com a prossecução das ações de reforma e com objetivo de melhorar gradualmente a assistência sanitária, os Ministérios da Justiça e do Interior assinaram, em 2004, um memorando de entendimento com o Ministério da Saúde (Misau) que prevê a prestação dos cuidados de saúde aos reclusos nos estabelecimentos de detenção e nas diferentes penitenciárias do País. As partes acordaram, dentre vários temas, os seguintes: assistência médica e técnica; concepção de programas e execução de projetos; fornecimento de equipamento hospitalar e meios de tratamento; abastecimento de medicamentos e outro material preventivo; apoio na formação do pessoal paramédico; reabilitação ou desenvolvimento de infraestruturas físicas para a continuidade dos objetivos do acordo.

Desse modo, a necessidade de verificar a viabilidade de avaliação (avaliabilidade) da atenção à saúde dos reclusos justifica-se por tratar-se de tema sensível e pouco explorado, bem como por ser necessário conhecer e compreender o ambiente sanitário penitenciário de modo a criar estratégia de ações e melhor intervir. Ademais, a população privada de liberdade possui uma situação epidemiológica peculiar devido às precárias condições e à superlotação existente nas prisões.

Diante desse contexto, o objetivo deste artigo é realizar um estudo de viabilidade de avaliação da atenção à saúde dos reclusos no Estabelecimento Penitenciário Provincial de Maputo (EPPM) - Moçambique com base na descrição da estrutura e dos processos de atenção à saúde no EPPM e na descrição dos contextos externos e organizacionais que interferem na atenção à saúde. 


\section{Metodologia}

Trata-se de estudo de caso único com abordagem qualitativa realizado em 2016 no EPPM, localizado na Província de Maputo, sul de Moçambique.

O estudo de viabilidade de avaliação, segundo Bezerra et al."1" se insere no âmbito de preparação de uma avaliação propriamente dita e consiste em entendimentos entre os envolvidos sobre o objeto e objetiva consensos sobre a necessidade ou não da realização da avaliação. Os mesmos autores referem que o estudo permite a preparação de um ambiente favorável a avaliações futuras, criando oportunidades para a utilização dos resultados pelos principais intervenientes. Para Thurston e Potvin ${ }^{\mathbf{1 2}}$, esse tipo de estudo possibilita entendimentos aprofundados sobre o objeto da pesquisa e uma apreciação prévia das possibilidades de sua avaliação, racionalizando recursos, frequentemente escassos para o processo avaliativo.

Este estudo de viabilidade de avaliação levou em consideração as seguintes etapas sugeridas por Thurston e Ramaliu ${ }^{13}$ : (a) delimitação do programa e identificação de metas, objetivos e atividades; (b) identificação e análise dos documentos da intervenção a ser avaliada; (c) construção do modelo lógico, tendo em consideração os recursos disponíveis; (d) supervisão do programa; (e) identificação dos usuários envolvidos na avaliação; e (f) elaboração de recomendações sobre o programa. A identificação desses elementos também foi utilizada em diversos estudos recentes ${ }^{\mathbf{1 4}, 15}$.

Para a realização deste estudo, privilegiou-se a combinação das seguintes técnicas de pesquisa: análise documental, observação direta e questionário, como forma de acumular dados com credibilidade. A coleta dos dados foi baseada em fontes primárias e secundárias. Os dados primários foram obtidos pelos questionários e observação direta, usando instrumentos semiestruturados. Os dados secundários advieram da análise da documentação institucional, legislação nacional, Plano Estratégico do Setor Saúde (Pess), decretos, diplomas ministeriais, leis e relatórios.

A figura 1 apresenta a estrutura do estudo de viabilidade de avaliação contendo as técnicas de coleta de dados, os documentos e os informantes-chave, que, por sua vez, foram os potenciais usuários identificados.

Figura 1. Estrutura do estudo de avaliabilidade da atenção à saúde dos reclusos do EPPM

\begin{tabular}{|l|}
\hline Informante-chave \\
\hline $\begin{array}{l}\text { Diretor Nacional } \\
\text { de Saúde Pública }\end{array}$ \\
\hline $\begin{array}{l}\text { Diretor Nacional do } \\
\text { Serviço de Operações } \\
\text { Penitenciárias }\end{array}$ \\
\hline $\begin{array}{l}\text { Diretor Nacional do } \\
\text { Serviço de Reabilitação } \\
\text { e Reinserção Social }\end{array}$ \\
\hline Diretor do EPPM \\
\hline $\begin{array}{l}\text { Chefe do } \\
\text { Departamento dos } \\
\text { Cuidados Sanitários }\end{array}$ \\
\hline
\end{tabular}

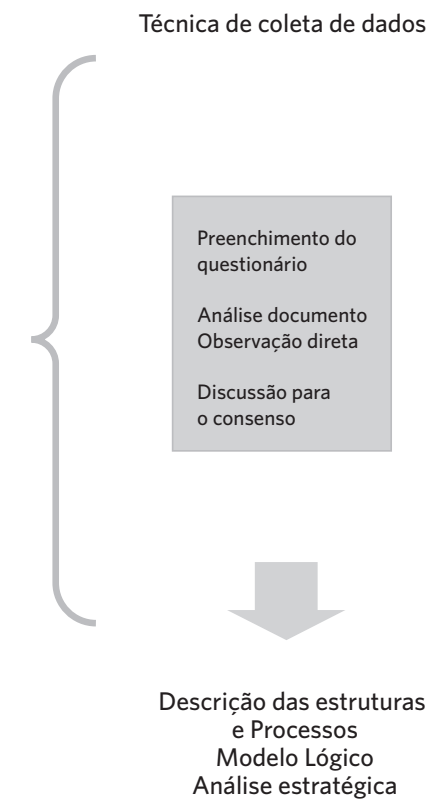


A figura 1 mostra que foram consultados o Decreto-Lei no 26.643, de 28 de Maio 1936, Diplomas Ministeriais, relatórios anuais do Misau e do Ministério da Justiça, Sernap, EPPM, Hospital Geral da Machava e Serviços de Saúde, Mulher e Ação Social da Matola (SSMAS). Inicialmente, foi realizada uma leitura superficial de todos os documentos acessados e, posteriormente, uma leitura em profundidade a fim de identificar os pontos para a descrição das estruturas e processos, identificação dos usuários potenciais e construção do modelo lógico da atenção à saúde no EPPM.

A observação direta dos serviços de atenção à saúde permitiu que dados fossem registrados à medida em que os fatos iam ocorrendo, de forma espontânea, sem a devida preparação, pois a melhor ocasião para o registro é no local onde a atividade é desenvolvida. O uso dessa técnica também consistiu na observação das práticas dos diferentes colaboradores do Sernap, funcionários e reclusos.

Elaborou-se um questionário auto aplicado, entregue a 28 pessoas e respondido por 21 informantes representantes da Direção Nacional da Assistência Médica (DNAM), Sernap, Hospital e SSMAS da Matola. Solicitou-se previamente o consentimento e autorização da Direção Geral do Sernap com o conhecimento do EP, Misau e da Direção Provincial de Saúde de Maputo. Os questionários foram entregues pessoalmente e antecedidos pela explicação dos objetivos da pesquisa e pela assinatura do Termo de Consentimento Livre Esclarecido (TCLE). Decidiu-se pelo questionário auto aplicado para evitar constrangimentos, visto que a principal pesquisadora do estudo possuía uma posição hierárquica no Sistema Penitenciário de Moçambique.

Optou-se por identificar os participantes da pesquisa com as letras PM para os dois profissionais do Posto Médico, PD para as duas Pessoas da Direção do EPPM, IC para Informante-Chave, i.e., os cinco Gestores do Misau e Sernap não profissionais de saúde, e PS para os doze Profissionais da Saúde do Serviço Nacional de Saúde (SNS). A numeração foi dada de acordo com a arrumação dos questionários. Todos os dados coletados e os registros do diário de campo utilizados foram analisados por meio da técnica de análise de conteúdo ${ }^{17}$ e categorizados em três áreas: Estrutura da Atenção à Saúde, Processos na Atenção à Saúde e Contexto Político-Organizacional.

$\mathrm{O}$ projeto de pesquisa foi submetido ao Comitê Nacional de Bioética em Saúde de Moçambique e aprovado por meio do parecer $n^{\circ} 34 / C N B S / 2016$. O estudo teve caráter confidencial e a identidade dos participantes foi mantida em anonimato e resguardada.

\section{Resultado e discussão}

\section{Estrutura da atenção à saúde no EPPM}

O EPPM tem capacidade de 800 vagas, é constituído por um bloco administrativo, um gabinete de assessoria jurídica, uma escola com cinco salas de aulas, um posto médico sem internamento, uma cozinha, dez pavilhões incluindo o pavilhão dos doentes da TB, uma gráfica, uma serralharia, uma alfaiataria, uma carpintaria, uma tecelagem, um balneário externo, um local para receber as visitas dos familiares e o recinto geral.

O posto médico localiza-se fora da área administrativa, possui dois consultórios, para médico e enfermagem, uma sala de tratamentos, uma sala de observações, que também funciona como sala de espera, ala administrativa, farmácia, dois sanitários, sendo um para os profissionais e um para os reclusos, uma copa e uma sala preparada para circuncisão médica voluntária. Não há laboratório, sala para colheita de sangue nem sala para esterilização de material. Ademais, falta água corrente. Na sala de tratamento clínico não há material suficiente para fazer curativos. As condições propícias para a transmissão do HIV, cuja prevalência é maior nos EPs, acentuam-se devido à carência material. A 
precariedade da estrutura física das unidades de saúde também foi encontrada no Brasil por Oliveira ${ }^{18}$, que refere gabinetes médicos sem ventilação adequada, sem local para a coleta de amostras de sangue e insuficiência de recursos materiais básicos, como maca para observação.

A equipe de saúde é constituída por um médico, dois enfermeiros gerais, uma agente polivalente elementar, uma servente que atende à farmácia e mais quatro agentes penitenciários que prestam apoio ao posto médico. Esse número de funcionários foi considerado insuficiente por todos os entrevistados. $\mathrm{O}$ quadro 1 indica as categorias e o número de profissionais de saúde necessários para uma melhor atenção sanitária.

Quadro 1. Categorias e número de profissionais de saúde necessários para o EPPM, 2017

\begin{tabular}{ll}
\hline Categoria dos Profissionais de saúde necessários & № de Profissionais \\
\hline Médico generalista & 2 \\
Médico dentista & 1 a 02 \\
Técnico de medicina & 1 a 2 \\
Enfermeiros & 3 a 4 \\
Assistente social & 1 \\
Psicólogo & 2 \\
Psiquiatra & 1 a 2 \\
\hline
\end{tabular}

Fonte: Elaboração própria.

O número de profissionais proposto foi considerado ideal para a atual população reclusa de cerca de três mil e pode possibilitar assistência nas $24 \mathrm{~h}$ do dia a exemplo do que acontece em alguns países como Brasil e Espanha, onde a assistência é garantida por uma equipe fixa composta por médico, enfermeiro, odonto-estomatologista, ou dentista, psicólogo, assistente social, auxiliar de enfermagem para um determinado número de reclusos ${ }^{19,20}$.

A insuficiência de recursos humanos em quantidade e qualidade na área da saúde e a falta de equipamentos médico-cirúrgicos associada ao tempo limitado de assistência para garantir atenção à saúde adequada resultam em uma deficiente prestação dos cuidados de saúde no Estabelecimento Penitenciário. Oliveira ${ }^{\mathbf{1 8}}$ tem o mesmo achado no seu artigo, elucidando que a equipe de saúde em duas unidades prisionais estudadas era insuficiente. Concomitantemente, Minayo e Ribeiro ${ }^{21}$ também discorreram sobre a escassez de profissionais de saúde, a demora nos atendimentos e, principalmente, quando o problema envolve $o$ atendimento emergencial.

\section{Processos na atenção à saúde no EPPM}

O posto médico funciona por oito horas nos dias úteis. Nos horários em que não opera, os doentes graves são transferidos para as US do SNS e os não graves aguardam para o dia seguinte. Para se dirigir ao posto médico, os reclusos são acompanhados pelo 'chefe de saúde'. O chefe de saúde é um recluso eleito pelos outros em coordenação com a direção do estabelecimento, cujo papel é dar informações do posto médico, acompanhar os doentes para assistência médica, providenciar e garantir a tomada diária dos medicamentos e representar o elo entre os reclusos e a direção para garantir a fluidez da informação.

A admissão do recluso na consulta tanto do enfermeiro como do médico obedece a um determinado fluxograma: 
Figura 2. Fluxo de atendimento dos reclusos do EPPM, 2017

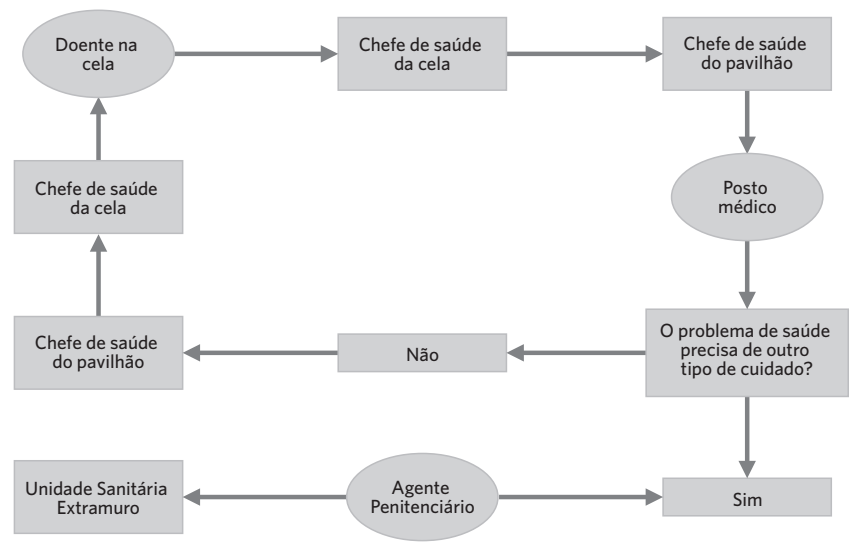

Fonte: Elaboração própria.

Existem pontos divergentes entre o que a literatura revela e a realidade no EPPM em relação ao fluxo para o atendimento do recluso doente. Enquanto, para Diuana et al. ${ }^{10}$, o guarda penitenciário desempenha papel preponderante, facilitando ou dificultando a ação, o acesso aos serviços de saúde, neste estudo, é papel atribuído ao recluso, que pode ser chefe da cela ou do pavilhão. Esse, por sua vez, pode facilitar ou dificultar o acesso aos serviços de saúde, considerando que, na prisão, predomina a 'lei do mais forte', sendo indispensável que o pessoal da saúde faça uma visita diária aos pavilhões para identificar casos que precisem de atenção.

Essa situação remete ao artigo de Le Marcis ${ }^{1}$, que descreve como os doentes mais fracos e com menores condições de pagar ao chefe dos reclusos são os menos capazes de ter acesso à assistência médica. Ou seja, é um arranjo não institucionalizado que passa a ser reconhecido como formal para a garantia do acesso no contexto penitenciário. Outros autores tais como Sánchez e Larouzé22 também consideram que o acesso aos serviços de saúde na prisão, que deveria ser disponível a qualquer recluso que necessite, é controlado ou pelo agente penitenciário ou pela hierarquia interna dos presos.

De acordo com a observação realizada, o atendimento no posto é feito sem nenhuma privacidade e as consultas são sempre acompanhadas pelo chefe da saúde, que exerce a sua autoridade. Essa presença inibe o recluso e não permite que exponha o seu real problema. Um aspecto muito importante, segundo Coyle $^{20}$, é o direito à privacidade e à confidencialidade durante a consulta médica, e, por questões de segurança o guarda ou qualquer acompanhante pode estar num local visível, mas fora do campo da audição.

Um dado importante relacionado com a atenção, também comprovado por Jólluskin et al. ${ }^{7}$, é que os reclusos recém-chegados ao EP apresentam-se com infeções de transmissão sexual e outras doenças transmissíveis, o que revela que essa população já ingressa com problemas de saúde, havendo necessidade de se garantirem ações de educação para saúde e medidas de prevenção regulares para evitar novas transmissões ou reinfecções. Tais atividades são garantidas pelos educadores de pares no posto de saúde e no ambiente prisional em geral. Esses educadores são reclusos ou funcionários com formação nas áreas de prevenção e promoção da saúde, incluindo sinais e sintomas de Aids, tuberculose, malária, direitos humanos, saneamento do meio e higiene. Em sua maioria, são chefes de saúde que apoiam o posto médico 
na sensibilização e mobilização de outros reclusos na adoção de medidas de prevenção ${ }^{3}$.

Ao ingressar no EP, o recluso é submetido a uma avaliação médica, acompanhada pelo preenchimento de uma ficha de entrada, que permite um diagnóstico rápido e precoce, possibilitando o acesso ao tratamento atempado, bem como a medidas de prevenção. Os profissionais de saúde entrevistados consideram importante a identificação precoce de doenças infectocontagiosas para a subsequente separação dos doentes:

[...] Triagem à entrada dos reclusos incluindo rastreios permanentes e separação de reclusos por faixa etária. (são sugeridos por PS10).

[...] Visitas regulares dos médicos aos reclusos, triagem do recluso à entrada para diagnosticar doenças infecto contagiosas. (por PS3).

Essa avaliação para a entrada está em consonância com as recomendações das Regras de Mandela 9 , que sugerem o atendimento à pessoa privada de liberdade, sempre que possível, antes de sua entrada no Estabelecimento Penitenciário. Os achados de Martins ${ }^{23}$ igualmente convergem sobre a avaliação clínica inicial do recluso após ingressar no EP, num prazo máximo de 24 horas.

Igualmente, os profissionais de saúde que prestam assistência nas unidades sanitárias extramuros sugerem que, para melhorar a assistência, é necessário encaminhar ou transferir os reclusos o quanto antes a fim de evitar o agravamento ou a morte. Nesse sentido, foi unânime o posicionamento de que se deve:

[...] Transferir a tempo os reclusos doentes para não chegarem em estado terminal nas US. (PS4).

[...] Encaminhar a tempo os reclusos doentes para beneficiarem do tratamento, respeitar as referências feitas pela US para outros hospitais com cuidados completos. (PS5).

O encaminhamento de reclusos doentes às unidades sanitárias do SNS é frequente, embora não recebam sempre o devido atendimento ou recebam alta hospitalar ainda em estado não satisfatório. Essa falta de sensibilidade e humanismo e o vaivém debilitam cada vez mais a saúde do recluso. A situação demostra uma clara negligência da assistência dada aos presos, confirmando a posição de Kölling, Silva e Sá5, que afirmam que não se pode tratar o recluso com desumanidade, que ser preso não significa perder sua condição humana ou seus direitos à cidadania.

$\mathrm{A}$ atenção à saúde no EPPM ainda não é completa, como se pode depreender pelas várias transferências realizadas para o serviço de estomatologia ou para realização de exames complementares de diagnóstico ${ }^{8}$. A diarreia, a malária, dermatites, infecções das vias respiratórias superiores, TB, hérnia inguinal e cárie dentária são os problemas de saúde que mais assolam o EPPM, sendo que o HIV e a Aids, algumas vezes associado à $\mathrm{TB}$, constituem a principal causa de morte. Outro agravo, não menos importante, é a hepatite, embora não existam estudos relatando essa doença no meio penitenciário moçambicano.

No que concerne às atividades preventivas e promoção de saúde, existe no posto médico, expostos e afixados nas paredes, materiais de Informação, Educação e Comunicação (IEC) sobre a prevenção da TB, HIV, doenças diarreicas etc., todos escritos em língua portuguesa. Martins ${ }^{23}$ menciona a baixa escolaridade ou até mesmo o analfabetismo que existe no seio dos reclusos como limitante para a percepção das mensagens, devendo a direção do EPPM e os profissionais de saúde escolher a comunicação verbal, o que será fundamental para sua compreensão e mudança de atitude. Entretanto, a dinâmica do posto é mais curativa e com poucas atividades preventivas. $\mathrm{O}$ aconselhamento em saúde, principalmente para doenças transmissíveis tais como o HIV e TB, é inexistente, embora fosse importante para a conscientização do recluso sobre a existência dessas doenças e seus métodos de prevenção. Há que se refletir sobre a inexistência ou incipiência de atividades de prevenção e 
promoção diante de uma situação de saúde tão precária nessa Penitenciária, principalmente em relação às doenças infecciosas.

Os profissionais de saúde exercem papel relevante na promoção da saúde quer seja pela distribuição de material educativo quer por palestras divulgando mensagens. É importante a divulgação da informação sobre o
HIV e Aids a toda a população penitenciária como forma de prevenir a transmissão entre esse grupo, assim como proteger a comunidade em geral23.

A coleta e análise dos dados resultou na elaboração do Modelo Lógico da Atenção à Saúde no EPPM (figura 3), o que permitiu a descrição da racionalidade da intervenção.

Figura 3. Modelo lógico da atenção à saúde aos reclusos do EPPM

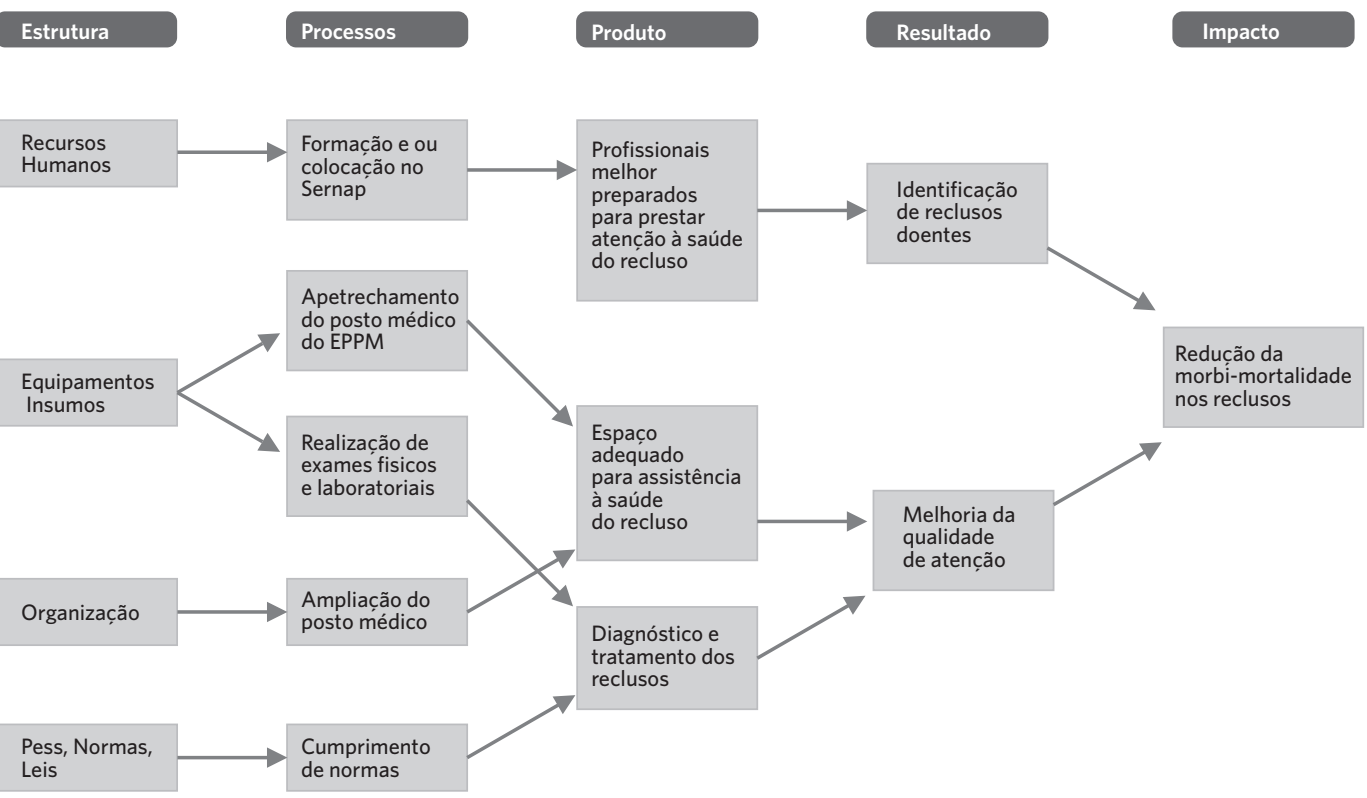

Fonte: Elaboração própria.

Pess - Plano Estratégico do Setor Saúde.

\section{Contexto político-organizacional do Estabelecimento Penitenciário}

No domínio da estrutura organizacional, o EPPM, por meio do memorando de entendimento assinado entre o Ministério da Justiça e o da Saúde, recebe apoio na área de assistência médica e exames compl ementares de diagnóstico nas unidades hospitalares do SNS, medicamentos, programas de rastreio da TB e testagem para o HIV. Nessa relação, pode-se identificar dois polos de poder: de um lado, a gestão penitenciária, que possui a tutela do recluso, assegurando as condições de reabilitação e reinserção social do mesmo, e, de outro, o SNS, que possui os serviços, programas, equipamento tecnológico e o conhecimento sobre os cuidados necessários para garantir a assistência à população penitenciária de forma adequada. Além disso, a penitenciária estabeleceu parcerias com algumas confissões religiosas para prestarem apoio psicossocial, espiritual e auxiliar a reabilitação do recluso. Similarmente, algumas Organizações Não Governamentais apoiam as atividades do saneamento do meio, construção de sanitários e formação dos educadores de pares. 
Por conseguinte, dada a importância que a saúde tem e, principalmente no contexto penitenciário devido a diversos fatores, tentou-se saber dos entrevistados que ações estratégicas podem ser adotadas para a melhoria da assistência.

[...] Considerando a saúde um direito fundamental e consagrado na constituição da República os reclusos têm direito à saúde e deve se beneficiar de todas as intervencões de Saúde Pública porque depois da reclusão voltam à comunidade e podem correr o risco de transmitir doenças ou ficar infectado se não adaptarem medidas de prevenção. (IC5).

A saúde das pessoas privadas de liberdade incontestavelmente é questão de saúde pública. Nos dizeres de Minayo e Constantino ${ }^{4}$, a convivência dos reclusos com as suas famílias e com os agentes e funcionários da penitenciária, pode disseminar doenças se as condições de saúde forem precárias.

Quando questionados sobre que melhorias poderiam ser realizadas de modo a garantir uma boa assistência aos reclusos, os entrevistados mencionaram questões de natureza administrativa - recursos humanos -, como a formação de quadros de pessoal da saúde, e estruturais - recursos materiais -, como a aquisição de equipamentos de saúde apropriados para a assistência dos reclusos:

[...] Construção de um Centro de Saúde penitenciário e apetrechamento com equipamento. Colocação de médicos enfermeiros, farmacêuticos e agentes serventuários. (IC3).

O IC2, em sua resposta, remete-nos a um dos princípios fundamentais da Constituição da República que é o direito à vida e à saúde, independentemente da situação em que o indivíduo se encontra. Contudo, as infraestruturas penitenciárias não concorrem para a efetivação de padrões humanizantes e, cada vez mais, se tornam uma realidade dura para as equipes de saúde que trabalham todos os dias para contribuir com a melhoria da saúde dos reclusos ${ }^{24}$.
[...] Formação de quadros de Saúde, nos níveis médio e superior, melhorar infraestruturas das penitenciárias para redução do confinamento, meIhorar postos de Saúde para melhorar o fluxograma do atendimento dos reclusos, apetrechamento em material médico e equipamento hospitalar, maior envolvimento do Misau. Maior abertura dos gestores penitenciários na discussão e adoção de pacotes de Saúde oferecidos à população em geral. (IC2).

O PM1 considera também a necessidade de melhoria das condições estruturais do serviço de saúde penitenciária:

[...] Melhorar as infraestruturas, aumentar compartimentos, laboratório, ATS, garantir água potável corrente, aumentar número de profissionais, ter dermatologista, psiquiatra, oftalmologista etc. Cirurgia, estomatologia e fisioterapia. (PM1).

As sugestões de índole administrativa resumiram-se à insuficiência de recursos humanos e à necessidade de formação e alocação de mais pessoal de outras áreas de especialidade, de modo a se criarem condições para garantir um atendimento 24 horas por dia. Embora Kölling et al. ${ }^{5}$ considerem que o aumento de profissionais especializados em uma determinada unidade não implique melhoria da assistência à saúde, porque existem outros fatores indispensáveis à melhoria da qualidade de vida $\mathrm{e}$ atenção à saúde, Damas ${ }^{25}$ e outros autores ${ }^{18}$ consideram que a existência de uma equipe de saúde multiprofissional é vital para minorar a demanda para outras unidades de saúde.

As sugestões de natureza estrutural relacionaram-se com o tamanho do posto, o tipo de serviços a serem prestados e a falta de recursos materiais. Relativamente às dimensões do posto, foi referenciado seu tamanho reduzido e ausência de vários compartimentos úteis para uma boa funcionalidade. A exiguidade de espaço físico, a carência de equipamento e outros materiais associados à insuficiência de recursos humanos constituem fatores que afetam e dificultam de algum modo uma boa 
prestação de cuidados de saúde aos reclusos, como revelam as falas de dois dos participantes do estudo:

[...] Dada à especificidade da população reclusa sugiro que se organize um serviço de Saúde penitenciária que inclua ações de promoção, preventivas, curativas e reabilitativas em particular nos principais centros prisionais dotados de $\mathrm{RH}$, materiais, financeiros e infraestruturas. (IC5).

[...] Previsão de uma parte do orçamento do Sernap para área de cuidados sanitários, construção de uma unidade hospitalar penitenciária com internamento em cada região. Formação de reclusos com escolaridade em matérias de Saúde. Estabelecimento de um sistema de monitoria. (IC2).

Tais sugestões fazem perceber que não existe um serviço de saúde que garanta atenção completa à saúde do recluso. Essa falta de recursos materiais e financeiros e a insuficiência de profissionais geram precariedade no atendimento. Os resultados apresentados mostram que a assistência ao recluso não é totalmente garantida pelo Sistema Penitenciário e muito menos pelo SNS.

O desconhecimento do memorando entre o Ministério da Justiça e o da Saúde pelos profissionais de saúde, aliado à falta de política clara para a assistência à saúde dos reclusos, não dispensa o dever de cuidar desse grupo já excluído por sua condição social. A desconexão entre o Sernap e o Misau possibilita que o atendimento ou atenção à saúde do recluso seja inadequada e insuficiente. A saúde é um direito de todo cidadão consagrado na CRM e um dever do Estado provê-la a todos sem discriminação. Existe a preocupação de o recluso usufruir o que está consagrado constitucionalmente, assim como da prevenção de transmissão de doenças para a comunidade, confirmando o que Diuana et al. ${ }^{10}$ afirmaram no seu estudo.

As atividades referentes à promoção de saúde e prevenção de doenças precisam ser mais intensificadas, considerando o problema da superlotação do estabelecimento e dos reclusos que dão entrada com situação ou suspeita de doenças transmissíveis. A literatura nos revela que essas doenças também são frequentes nesse meio 5 . De acordo com o que consta no relatório em Moçambique, a TB, ITs, HIV e Aids são doenças que afetam a população reclusa moçambicana ${ }^{3}$.

Esses resultados do estudo indicam que o atual modelo de assistência não atende cabalmente aos problemas de saúde e às necessidades de assistência dos reclusos. Nesse contexto, havendo uma visão clara das normas, estrutura e processos de atenção à saúde prisional, julga-se pertinente e viável a realização de uma avaliação.

As principais limitações desta pesquisa envolveram a insuficiência ou falta de informação nos relatórios do Misau referentes ao atendimento dos reclusos, bem como a ausência de estudos referentes à atenção à saúde dos reclusos em Moçambique. O uso do questionário auto aplicado não permitiu aprofundar mais as perguntas. Apesar de a investigação ser realizada numa área na qual a pesquisadora tem responsabilidades sobre a sua execução, destaca-se que o acesso ao Sistema Penitenciário e o cuidado nas coletas foi o que permitiu a realização desse estudo.

\section{Considerações finais}

Neste estudo de avaliabilidade, objetivou-se agregar diferentes perspectivas por meio de diferentes fontes de informação, obtendo, desse modo, a comprovação ou contradições entre os achados, o que permitiu constatar que a atenção à saúde do recluso é um assunto pouco debatido e não está incluído de forma devida nas políticas de saúde do SNS. Ainda que a população reclusa seja atendida nas unidades hospitalares circunvizinhas dos EPs, não existe nenhuma referência, informação ou abordagem a esse grupo populacional nos relatórios do Misau no geral. 
*Orcid (Open Researcher and Contributor ID).
O estudo de caso realizado trouxe elementos que puderam contribuir para o desenho de uma futura avaliação da atenção à saúde dos reclusos em Maputo ou mesmo em Moçambique. Muitos foram os achados que revelam a necessidade de ajustes e adequação na estrutura e nos processos da atenção à saúde dos reclusos, do envolvimento de atores-chave e de priorização na agenda da política de saúde do País. Contudo, há que se incorporarem esforços de acompanhamento e avaliação da qualidade das ações existentes e de indução para a implantação de novas ações.

Para que os reclusos convivam em ambiente salubre, existem competências que devem ser compartilhadas, sabendo-se, evidentemente, que a questão infra estrutural geral, incluindo a construção dos postos de saúde, compete ao Ministério da Justiça. Mas o SNS tem a obrigação de equipar e alocar recursos humanos para garantir o atendimento segundo o que foi assinado no memorando.

A falta de uma Política Nacional de Saúde atualizada em Moçambique que inclua a saúde penitenciária não permite uma orientação clara quanto aos procedimentos e ações que devem ser desenvolvidas em meio penitenciário quanto à promoção, prevenção e assistência médica dos reclusos. O problema de superlotação do EP, associado a uma atenção à saúde inadequada, cria condições para o surgimento de diversas doenças infectocontagiosas e para o aumento da sobreposição de vulnerabilidade individual, social e programática.

Há a terceirização ou delegação das atividades dos profissionais de saúde, principalmente nas de promoção, repassando-as para as mãos dos educadores de pares ou chefe de saúde, o que gera seu empoderamento no estabelecimento penitenciário e um 'conforto' não somente para o pessoal da saúde como também para os guardas.

Dada a importância da atenção à saúde dos reclusos e a conclusão de que existe viabilidade para avaliação, tem-se a convicção que estudos futuros serão levados a cabo com base nos pontos críticos levantados neste estudo. Nesse caso, tem-se como recomendações: a criação de materiais nos diferentes idiomas do País e para diferentes grupos culturais para facilitar a compreensão dos reclusos, e que o material exposto deve ser simples e com linguagem clara e acessível; o aumento do número de profissionais para garantir uma assistência $24 \mathrm{~h}$ e o cumprimento da tomada da medicação; a supervisão e o apoio técnico regular pelo SNS para suprir as dificuldades em material médico e gestão de medicamento; a reabilitação e ampliação do posto de saúde de modo a melhorar a prestação de cuidados; a alocação de uma viatura tipo ambulância para transferência dos doentes imediatamente para as unidades sanitárias extramuros; a criação de um sistema de informação para o monitoramento devido das ações e desfechos de saúde no EPPM; e a atualização da Política Nacional de Saúde, onde se deve incluir a saúde penitenciária.

De modo geral, há a necessidade de o SNS assumir seu papel de cuidador da saúde de todos os cidadãos moçambicanos, incluindo a dos reclusos. Os Ministérios da Justiça, assuntos constitucionais e religiosos e o da saúde devem conciliar esforços como forma de criar e harmonizar políticas que promovam e melhorem a saúde no sistema penitenciário. A atuação numa perspectiva mais integrada pode contribuir para a construção de um sistema de saúde penitenciário mais ancorado nos direitos humanos e no acesso mais equânime à saúde nos Estabelecimentos Penitenciários de Moçambique, assim como nos de outros países.

\section{Colaboradoras}

Anli C (0000-0003-3457-3707)* participou da concepção do projeto, coleta, análise e interpretação dos dados, revisão de conteúdo e da redação do artigo. Cruz MM (00000002-4061-474X)* participou da concepção do projeto, interpretação dos dados, revisão de conteúdo e da aprovação final da versão a ser publicada. Oliveira LGD (0000-0002-82084134)* participou da concepção do projeto, revisão de conteúdo e da aprovação da versão final a ser publicada. 


\section{Referências}

1. Le Marcis F. A impossível governança da saúde em prisão? Reflexões a partir da MACA (Costa do Marfim). Ciênc. Saúde Colet. 2016; 21(7):2011-20.

2. Walmsley R. World prison population list. [internet]. 2018 [acesso em 2020 ago 22]. Disponível em: http:// www.Prisionstudies.org/sites/default/files/resources/downloads/wppl.12.pdf.

3. Moçambique. Serviço Nacional Penitenciário. Relatório anual. Maputo: Ministério do Interior; 2019.

4. Minayo MCS, Constantino R. Deserdados sociais: condições de vida e saúde dos presos do Estado do Rio de Janeiro. Rio de Janeiro: Editora FHC; 2016.

5. Kölling GJ, Silva MBB, Sá MCD. O Direito à Saúde no Sistema Prisional. Temp - Act de Saúde Coletiva. 2013; 7(1)281-97.

6. Moçambique. Constituição, 2004. Constituição da República de Moçambique. Maputo: Assembleia da República; 2004.

7. Jólluskin G, Castro-Rodrigues A, Silva I, et al. Saúde e reclusão: de uma breve contextualização do fenómeno ao papel dos profissionais de saúde. Rev sociologia. 2014; (13):89-102.

8. Moçambique. Serviço Nacional Penitenciário. Relatório anual. Maputo: Ministério da Justiça; 2017.

9. Organização das Nações Unidas. Regras de Mandela: Regras Mínimas das Nações Unidas Para o Tratamento de Presos. Brasília, DF: ONU; 2016.

10. Diuana V, Lhuilier D, Sánchez AR, et al. Saúde em prisões: representações e práticas dos agentes de segurança penitenciária no Rio de Janeiro, Brasil. Cad. Saúde Pública. 2008; 24(8):1887-1896.

11. Bezerra LCA, Cinthia KAA, Yluska ACR, et al. Identificação e caracterização dos elementos constituintes de uma intervenção: pré-avaliação da política ParticipaSUS. Ciênc. Saúde Colet. 2012; 17(4):883-900.
12. Thurston WE, Potvin L. Evaluability Assessment: A Tool for Incorporating Evaluation in Social Change Programmes. Evaluation. 2003; 9(4):453-69.

13. Thurston WE, Ramaliu A. Evaluability assessment of survivors of torture program: lessons learned. Can J Program Eval. 2005; 20:1-25.

14. Silva RN, Guarda FRB, Hallal PC, et al. Avaliabilidade do Programa Academia da Saúde no Município do Recife, Pernambuco, Brasil. Cad. Saúde Pública. 2017; 33(4):e00159415.

15. Miranda WD, Guimarães EAA, Campos DS, et al. Programa Nacional de Suplementação de Vitamina A no Brasil: um estudo de avaliabilidade. Rev Panam Salud Publica. 2018; (42):e182.

16. Oliveira LGD. Avaliação da implantação do Programa de Controle da Tuberculose em unidades prisionais de dois estados brasileiros [tese]. Rio de Janeiro: Escola Nacional de Saúde Pública Sergio Arouca; 2014.

17. Bardin L. Análise de Conteúdo. São Paulo: Edições $70 ; 2016$.

18. Oliveira LGD, Natal S, Camacho LAB. Análise da implantação do Programa de Controle da Tuberculose em unidades prisionais no Brasil. Cad. Saúde Pública. 2015 ; 31(3):543-554.

19. Arroyo JM, Astier P. Calidad asistencial en Sanidad Penitenciaria. Análisis para un modelo de evaluación. Rev Esp Sanid Penit. 2003; (5):60-76.

20. Coyle A. Administração Penitenciaria: Uma abordagem de Direitos Humanos. Londres: International Centre for prision studies; 2002.

21. Minayo MCS, Ribeiro AP. Condições de saúde dos presos do estado do Rio de Janeiro, Brasil. Ciênc. Saúde Colet. 2016; 21(7): 2031-2040.

22. Sánchez A, Larouzé B. Controle da tuberculose nas 
prisões, da pesquisa à ação: a experiência do Rio de Janeiro, Brasil. Ciênc. Saúde Colet. 2016; 21(7):20712079.

23. Martins JCB. A prática da saúde em ambiente Prisional: Relação entre Profissionais de Saúde e Reclusos [monografia]. Porto: Faculdade de Ciências Humanas e Sociais, Universidade Fernando Pessoa; 2013.

24. Garrido Cardoso HHG. A Saúde dos detentos no sistema penitenciário brasileiro: Uma análise de um Instituto Penal do Estado do Rio de Janeiro. [disser- tação]. Porto: Faculdade de Ciências Humanas e Sociais, Universidade Fernando Pessoa; 2019.

25. Damas FB. Assistência e Condições de Saúde nas Prisões de Santa Catarina, Brasil. Rev. Saúde Públ. 2012; 5(3):6-22.

Recebido em 26/12/2019

Aprovado em 28/08/2020

Conflito de interesses: inexistente

Suporte financeiro: não houve 